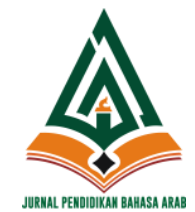

\author{
Alibbaa': Jurnal Pendidikan Bahasa Arab \\ Vol. 2 No. 2, Juli 2021 \\ P-ISSN: 2721-1606 | E-ISSN: 2716-4985 \\ doi: https://doi.org/10.19105/allb.v2i2.4755
}

\title{
Problematika Pembelajaran Maharah Qiraah Daring: Studi Kasus Terhadap Mahasiswa PBA IAIN Syaikh Abdurrahman Siddik Bangka Belitung
}

\author{
Ela Isnani Munawwaroh \\ State Islamic University of Syaikh Abdurrahman Siddik Bangka Belitung, Indonesia \\ E-mail: elaisnani@gmail.com
}

\begin{abstract}
Online learning during this pandemic poses many problems. A common problem is that not all students have smartphones or a good network in their homes. Therefore, this study is intended to see more about what problems students face in learning reading skills. This study used a quantitative approach with descriptive methods. The subject of this research is students in the Arabic education program in the 4th semester. To collect data, the researcher used questionnaires and analyzed them using percentage techniques. The results of this research showed that the problems in learning reading skills faced by students of the Arabic education program IAIN SAS Bangka Belitung include: 1) Linguistic Aspect. More than $50 \%$ of students have poor language skills, especially in the mastery of nahwu and sharf, and 2) Non-linguistic Aspect. There are no significant problems, except for problems with the lost network caused by changes in weather or power outages.
\end{abstract}

Keywords: reading skill, online learning 


\section{Pendahuluan}

Pembelajaran di masa pandemi ini menuntun seluruh lapisan civitas akademika pada suatu kebiasaan baru, yaitu pembelajaran daring (dalam jaringan), atau yang dikenal dengan pembelajaran online. Namun demikian, pembelajaran daring juga menyebabkan munculnya permasalahan baru, karena tidak semua pembelajaran bisa dilaksanakan secara daring. Beberapa masalah yang muncul di antaranya adalah sulitnya siswa dalam memahami pelajaran dan tidak adanya motivasi yang kuat untuk belajar ${ }^{1}$. Selain masalah tersebut, terdapat pula permasalahan lain, yaitu kurangnya ketersediaan infrastruktur teknologi telekomunikasi, multimedia, informasi dan platform yang mendukung proses kegiatan belajar mengajar secara daring sehingga hal tersebut menjadi penghambat jalannya pembelajaran. ${ }^{2}$

Pembelajaran qira'ah tarbawiyah sendiri merupakan salah satu mata kuliah wajib yang harus diambil oleh mahasiswa Program Studi (Prodi) Pendidikan Bahasa Arab (PBA) IAIN Syaikh Abdurrahman Siddik Bangka Belitung (SAS Babel). Mata kuliah ini merupakan mata kuliah lanjutan dari mata kuliah maharotul qiroah. Fokus pembelajaran dari dua mata kuliah ini sama, yaitu untuk meningkatkan keterampilan membaca tulisan berbahasa Arab mahasiswa Prodi PBA. Proses pembelajaran qiroah mengharuskan keaktifan mahasiswa hampir dalam seluruh kegiatan pembelajaran, karena hanya dengan cara tersebut mahasiswa akan berlatih meningkatkan keterampilan dalam membaca dan dosen bisa menilai secara langsung kemampuan mahasiswa sekaligus memperbaiki kesalahan yang dilakukan. Dalam keterampilan qira'ah sendiri, kemampuan mahasiswa bisa dilihat dari tiga indikator, yaitu membunyikan huruf, kata, dan kalimat; mengenali struktur kalimat dengan memberikan harakat pada huruf, kata, dan kalimat; serta menemukan makna dari teks. ${ }^{3}$

\footnotetext{
1 Annisa Nurul Fadilla, Ayu Suci Relawati, and Nani Ratnaningsih, "PROBLEMATIKA PEMBELAJARAN DARING PADA PEMBELAJARAN MATEMATIKA DI MASA PANDEMI COVID-19", Jurnal Jendela Pendidikan, Vol. 1 No. 2, 2021: 48-60.

${ }^{2}$ Rudi Haryadi and Fitria Selviani, "PROBLEMATIKA PEMBELAJARAN DARING DI MASA PANDEMI COVID-19", Academy of Education Journal, Vol. 12 No. 2, 2021: 254.

${ }^{3}$ Ahmad Rathomi, "Pembelajaran Bahasa Arab Maharah Qira'Ah Melalui Pendekatan Saintifik", Ta'dib: Jurnal Pendidikan Islam, Vol. 8 No. 1, 2019: 58.
} 
Namun di masa pandemi ini, dosen merasa kesulitan menemukan metode pembelajaran yang sesuai. Berbagai metode sudah dicoba untuk diterapkan agar setiap mahasiswa tetap aktif dalam kegiatan belajar mengajar. Contohnya, dosen menggunakan aplikasi video conference baik menggunakan zoom cloud meeting ataupun google meet. Namun, penggunaan media ini terkadang menimbulkan kendala seperti lemahnya sinyal ataupun kondisi cuaca yang tidak menentu. Selain itu, sebagian dosen juga menggunakan media WhatsApp Group dalam pembelajaran maharah qiroah dengan menerapkan metode yang sebaik mungkin agar mahasiswa tetap aktif dalam proses pembelajaran. Seperti memberikan tugas sejak awal kepada mahasiswa untuk membaca, menerjemahkan ataupun menganalisis teks bacaan yang ada. Kemudian pada saat jam perkuliahan mahasiswa diminta untuk membaca hasil tugasnya masingmasing untuk kemudian disimak bersama-sama dan dikoreksi oleh dosen.

Permasalahan lebih lanjut kemudian adalah tidak semua mahasiswa menyimak proses pembelajaran secara serius. Hal ini terlihat ketika dosen meminta mahasiswa untuk membaca ulang bacaan ataupun menerjemahkannya ke dalam bahasa Indonesia, masih banyak yang melakukan kesalahan dalam membaca walaupun sudah dibaca oleh teman-teman sebelumnya.

Dalam penelitian terdahulu, juga ditemukan beberapa kendala yang tidak jauh beda dengan permasalahan di atas, diantaranya:

Pertama, artikel yang ditulis oleh Ahmad Syagif Hannany Mustaufy dengan judul "problematika pembelajaran bahasa Arab menggunakan aplikasi WhatsApp selama pandemi covid-19 pada siswa Madrasah Ibtidaiyah di kota Bima". Hasil penelitian tersebut menyebutkan bahwa penggunaan aplikasi WhatsApp dalam pembelajaran bahasa Arab di jenjang Madrasah Ibtidaiyah lebih banyak memfokuskan pada aspek mufradat dan tarkib serta lebih relevan untuk peningkatan maharah qira'ah dan kitabah. Adapun problematika yang muncul antara lain, pemberian materi yang kurang efektif dan kurang menyentuh aspek fonologi (ashwat), validitas hasil tugas yang rendah dikarenakan tugas yang diberikan tidak dikerjakan oleh siswa secara mandiri. Dari aspek lain, muncul problem dimana masih ada siswa yang tidak memiliki smartphone, biaya mahal yang harus dikeluarkan untuk membeli smartphone, pulsa, ataupun paket internet, dan 
minimnya pendampingan dari orangtua terhadap anak untuk melaksanakan proses belajar. ${ }^{4}$

Kedua, artikel yang ditulis oleh Dwi Felita Corinna dkk dengan judul "Problematika pembelajaran bahasa Arab secara daring: Studi kasus mahasiswa program studi bahasa dan kebudayaan Arab Universitas Al-Azhar Indonesia". Hasil penelitiannya menyebutkan bahwa kendala yang paling sering dihadapi oleh mahasiswa saat pembelajaran daring adalah terkait dengan masalah jaringan. Adapun terkait dengan kemahiran membaca, problem yang muncul adalah sulitnya responden dalam memahami teks. Hal tersebut disebabkan oleh lemahnya kompetensi mahasiswa dalam memberikan harokat serta menerjemahkan literatur Bahasa Arab. ${ }^{5}$

Ketiga, artikel yang ditulis oleh Thityn Ayu Nengrum dkk, dengan judul "Kelebihan dan Kekurangan Pembelajaran Luring dan Daring dalam pencapaian Kompetensi Dasar kurikulum bahasa Arab di Madrasah Ibtidaiyah 2 Kabupaten Gorontalo". Salah satu hasil penelitian tersebut menyebutkan bahwa beberapa kendala yang ditemukan dari pembelajaran daring adalah adanya siswa yang tidak mengerjakan tugas dengan alasan tidak memiliki smartphone, tidak ada sinyal maupun kuota internet. ${ }^{6}$

Keempat, artikel yang ditulis oleh Saiul Anah, dengan judul "Pembelajaran Bahasa Arab Daring (Studi Kasus mahasiswa Hukum Keluarga Islam (HKI) STAI Taruna Surabaya)". Ia menyebutkan bahwa kendala yang dirasakan oleh dosen dalam pembelajaran daring adalah kurangnya kesempatan dosen untuk memantau kemampuan mahasiswa secara langsung dan banyaknya mahasiswa yang tidak hadir

${ }^{4}$ Ahmad Syagif, "PROBLEMATIKA PEMBELAJARAN BAHASA ARAB MENGGUNAKAN APLIKASI WHATSAPP SELAMA PANDEMI COVID-19 PADA SISWA MADRASAH IBTIDA'IYAH DI KOTA BIMA", Fashluna: Jurnal Pendidikan Dasar Dan Keguruan, Vol. 1 No. 2, 2020: 66-79.

5 Dwi Felita Corinna, Intan Rembulan, and Faisal Hendra, "PROBLEMATIKA PEMBELAJARAN BAHASA ARAB SECARA DARING: STUDI KASUS MAHASISWA PROGRAM STUDI BAHASA DAN KEBUDAYAAN ARAB UNIVERSITAS AL-AZHAR INDONESIA", Prosiding Konferensi Nasional Bahasa Arab, Vol. 6 No. 6, 2020: 69-78.

${ }^{6}$ Thityn Ayu Nengrum, Najamuddin Pettasolong, and Muhammad Nuriman, "Kelebihan dan Kekurangan Pembelajaran Luring dan Daring dalam Pencapaian Kompetensi Dasar Kurikulum Bahasa Arab di Madrasah Ibtidaiyah 2 Kabupaten Gorontalo", Jurnal Pendidikan, Vol. 30 No. 1, 2021: 1-12. 
dalam perkuliahan. Sedangkan kendala yang dirasakan oleh mahasiswa adalah kurang bisa memahami materi dan koneksi jaringan internet yang lemah. ${ }^{7}$

Kelima, skripsi yang ditulis oleh Shintia Wulandari, dengan judul "Problematika guru selama pembelajaran daring dengan menggunakan aplikasi WhatsApp Group pada mata pelajaran bahasa Arab pada siswa kelas V di MI An-Nizham kota Jambi". Hasil penelitiannya menyebutkan bahwa kendala yang dihadapi dari pembelajaran daring diantaranya; terhambatnya komunikasi antar guru dan siswa yang menyebabkan rendahnya kualitas belajar anak. Selain itu, pembelajaran dengan menggunakan media WhatsApp tersebut menuntut guru untuk kreatif membuat video pembelajaran sendiri. Hal tersebut justru dapat membuat para guru terkuras waktu dan tenaganya untuk mempersiapkan materi. ${ }^{8}$

Namun demikian, dari beberapa penelitian di atas, dapat dilihat letak persamaan dengan penelitian yang penulis lakukan, yaitu samasama membahas mengenai pembelajaran daring. Tetapi terdapat beberapa perbedaan antara penelitian sebelumnya dengan penelitian yang penulis lakukan, yaitu pada materi pembelajaran, yang mana penulis memfokuskan pada pembelajaran qira'ah, yang merupakan salah satu dari empat kemahiran berbahasa Arab. Selain itu, obyek penelitian yang penulis pilih adalah pada mahasiswa Perguruan Tinggi yang mana dalam hal ini penulis memilih mahasiswa Prodi Pendidikan Bahasa Arab sebagai responden.

Tujuan dilakukannya penelitian ini adalah untuk mengetahui masalah-masalah atau kendala-kendala yang muncul sebagai akibat dari pelaksanaan pembelajaran secara daring dalam perkuliahan maharah qira'ah. Hasil dari penelitian ini nantinya diharapkan bisa menjadi pijakan bagi pengajar dalam menentukan materi, metode, media, dan juga evaluasi yang tepat dalam melaksanakan perkuliahan maharotul qira'ah.

${ }^{7}$ Saiul Ana, "PEMBELAJARAN BAHASA ARAB DARING (Studi Kasus Mahasiswa Hukum Kelurga Islam (HKI) STAI Taruna Surabaya)", Al-Fakkaar, Vol. 1, No. 2, 2020: 18-41.

8 WULANDARI SHINTIA, Mahluddin Mahluddin, and Imran Imran, "PROBLEMATIKA GURU SELAMA PEMBELAJARAN DARING DENGAN MENGGUNAKAN APLIKASI WHATSAPP GROUP PADA MATA PELAJARAN BAHASA ARAB PADA SISWA KELAS V DI MI AN-NIZHAM KOTA JAMBI" (UIN Sulthan Thaha Saifuddin Jambi, 2021). 


\section{Metode Penelitian}

Penelitian ini merupakan penelitian survei deskriptif, dimana penulis berupaya menjelaskan kondisi atau sikap yang ada saat ini. ${ }^{9}$ Penelitian survei ini bersifat deskriptif dengan pendekatan kuantitatif. Penelitian ini dilaksanakan pada Prodi PBA IAIN SAS Babel. Subyek penelitiannya adalah mahasiswa Prodi PBA Semester IV (empat) yang sedang mengambil perkuliahan Qiroah Tarbawiyah sebanyak 30 orang. Alat pengumpulan data yang digunakan berupa angket atau kuesioner. Untuk menganalisis data tersebut digunakan rumus statistik presentase dan analisis secara deskriptif. Setelah data dikelompokkan, selanjutnya disajikan dalam bentuk data yang mudah dibaca dan disimpulkan dengan teknik presentase.

\section{Hasil dan Pembahasan}

\section{Problematika Pembelajaran Bahasa}

Dalam pembelajaran bahasa, permasalahan yang muncul dalam proses pembelajaran dikelompokkan ke dalam problem linguistik dan non linguistik. Problem linguistik merupakan problem yang berkaitan dengan unsur bahasa itu sendiri, yang meliputi tata bunyi, kosakata, tata kalimat dan tulisan. ${ }^{10}$ Sedangkan problem non linguistik merupakan problem yang berkaitan dengan unsur di luar unsur kebahasaan, seperti perbedaan sosiokultural ataupun problem metodologis ${ }^{11}$.

\section{Aspek Linguistik}

Aspek linguistik meliputi aspek tata bunyi, kosakata, tata kalimat, dan tulisan bahasa Arab.

Dalam bahasa Arab, terdapat beberapa tata bunyi yang tidak ada dalam bahasa Indonesia, seperti huruf $ث$ (tsa), o(ha), خ (kha), ذ (dza), ض ض (dhad) b ط ط (zha), ع ('ain), dan غ (ghain). Karena itu, pelajar Indonesia harus memahami dan menguasai tata bunyi bahasa Arab sehingga dapat membedakan antar huruf, membacanya dan melafalkan huruf-huruf tersebut dengan benar.

${ }^{9}$ Morrisan, Metode Penelitian Survei, 5th edition (Depok: Prenada Media Group, 2018), 13.

${ }^{10}$ Acep Hermawan, Metodologi Pembelajaran Bahasa Arab (Bandung: PT. Remaja Rosdakarya, 2011), 30

11 Syamsuddin Asyrofi, Metodologi Pembelajaran Bahasa Arab (Yogyakarta: Idea Press, 2010), 26 
Sedangkan terkait dengan kosakata, problem yang muncul adalah lemahnya penguasaan kosakata bahasa Arab yang dimiliki oleh mahasiswa. Untuk meningkatkan penguasaan kosakata mahasiswa, diperlukan adanya keinginan dan usaha yang keras dari mahasiswa untuk menghafal ataupun mengkaji berbagai teks bahasa Arab dengan menggunakan kamus untuk mencari arti kata yang dibaca.

Selain itu, problem yang terkait dengan kosakata ini juga dikarenakan adanya konjugasi (tashrif), yaitu perubahan kata dengan pola-pola tertentu yang menimbulkan makna tertentu, dan adanya pergeseran arti bahasa Arab yang memiliki kemiripan dengan bahasa Indonesia.

Selanjutnya, terdapat ilmu nahwu yang membahas tentang bagaimana seharusnya membaca kalimat bahasa Arab dengan benar sesuai dengan kaidah-kaidah yang berlaku dalam bahasa Arab. Selain itu ada juga ilmu sharf yang merupakan ilmu yang membahas tentang tata cara merubah suatu kata dari satu bentuk ke bentuk yang lain untuk menghasilkan makna yang berbeda-beda. Kedua ini saling melengkapi satu sama lain, terlebih dalam pembelajan qiroah. Pembelajaran qiroah biasanya menekankan kemampuan dalam bidang ilmu nahwu dan ilmu sharf agar kalimat berbahasa Arab yang biasanya tidak memiliki harakat bisa dibaca dengan baik dan benar.

Tulisan Arab memiliki perbedaan dengan tulisan latin. Dalam bahasa Arab, tulisannya dimulai dari kanan ke kiri. Huruf-huruf dalam bahasa Arab pun memiliki variasi dalam penulisannya saat ia berada di awal, tengah, atau di akhir kata. Ada huruf yang bisa disambung, dan ada juga huruf yang tidak bisa disambung. Sedangkan dalam tulisan latin ditulis dari arah kiri ke kanan. Huruf dalam tulisan latin pun hanya terdiri dari huruf besar dan huruf kecil. Melihat perbedaan ini, maka akan cukup sulit bagi orang Indonesia untuk menulis tulisan Arab. Mereka harus belajar terlebih dahulu khusus terkait dengan tulisan Arab ini.

\section{Aspek non-Linguistik}

\section{a. Faktor Sosio-Kultural}

Faktor sosio-kultural ini erat kaitannya dengan lingkungan sosial budaya tempat mahasiswa berada. Lingkungan sosial yang akrab dengan bahasa Arab seperti lingkungan pesantren yang kesehariannya menggunakan bahasa Arab akan memudahkan mahasiswa untuk belajar bahasa Arab. 
Demikian pula sebaliknya, semakin jarang mahasiswa berinteraksi dengan lingkungan yang tidak akrab dengan bahasa Arab, maka akan sulit baginya untuk belajar bahasa Arab.

\section{b. Faktor Buku Ajar}

Selain faktor sosio-kultural di atas, faktor buku ajar yang digunakan juga menjadi salah satu problem dalam pembelajaran bahasa Arab. Oleh karena itu, dalam memilih buku ajar, pengajar harus memperhatikan prinsip-prinsip penyajian materi bahasa Arab sebagai bahasa asing yang berupa pemilihan materi yang memang diperlukan oleh pelajar sesuai dengan tingkatannya, berjenjang, dan tema yang disajikan saling memiliki kaitan dengan tema lainnya sehingga bisa saling menguatkan ${ }^{12}$.

\section{Problematika Pembelajaran Online Mata Kuliah Qiroah Pada Mahasiswa Pba Iain Syaikh Abdurrahman Siddik Bangka Belitung}

Berdasarkan angket yang penulis berikan kepada mahasiswa dengan jumlah 30 orang, bisa penulis deskripsikan hasilnya sebagai berikut:

1. Aspek Linguistik

Pada aspek tata bunyi bahasa Arab, dihasilkan persentase tertinggi dalam memahami tata bunyi bahasa Arab sekitar 62,5\% pada kategori baik, persentase tertinggi dalam mengidentifikasi tata bunyi bahasa Arab sekitar 68,75\% pada kategori baik, persentase tertinggi dalam kemampuan membaca tata bunyi bahasa Arab sekitar $62,5 \%$ pada kategori baik, dan persentase tertinggi dalam kemampuan melafalkan tata bunyi bahasa Arab sekitar 62.5\% pada kategori baik. Melihat hal ini, bisa disimpulkan bahwa mahasiswa memiliki kemampuan yang baik dalam aspek linguistik, sehingga pada aspek tata bunyi tidak menjadi problem utama dalam pembelajaran maharah qiro'ah daring mahasiswa.

Pada aspek kosa kata bahasa Arab, dihasilkan persentase tertinggi dalam memahami kosakata bahasa Arab sekitar 56,25\% pada kategori baik, persentase tertinggi dalam kemampuan membaca kosakata bahasa Arab sekitar 56,25\% pada kategori baik, persentase tertinggi dalam kemampuan melafalkan kosa kata bahasa

\footnotetext{
${ }^{12}$ Hermawan, Metodologi Pembelajaran Bahasa Arab. 42
} 
Arab sekitar $68,75 \%$ pada kategori baik, dan persentase dalam kemampuan menerjemahkan kosaka bahasa Arab sekitar 68,75\% pada kategori baik. Dengan demikian, bisa kita simpulkan bahwa kemampuan mahasiswa pada aspek kosa kata sudah baik, dan tidak menjadi problem utama bagi sebagian besar mahasiswa.

Pada aspek tata bahasa Arab, persentase tertinggi dalam pemahaman ilmu nahwu sekitar 56,25\% pada kategori tidak baik, persentase dalam pemahaman ilmu sharf sekitar $56,25 \%$ pada kategori tidak baik, persentase tertinggi kemampuan dalam menerapkan ilmu nahwu sekitar 68,75\% pada kategori tidak baik, dan persentase tertinggi kemampuan dalam menerapkan ilmu sharf sekitar 56,25\% pada kategori tidak baik. Dengan demikian, bisa disimpulkan bahwa kemampuan mahasiswa pada aspek tata bahasa Arab kurang baik, sehingga hal ini menjadi problem utama bagi mereka dalam pembelajaran maharah qira'ah.

Pada aspek tulisan bahasa Arab, persentase tertinggi kemampuan mahasiswa dalam mengenal tulisan Arab sekitar 75\% pada kategori baik, persentase tertinggi kemampuan mahasiswa dalam mengidentifikasi tulisan Arab sekitar $68,75 \%$ pada kategori baik, persentase tertinggi kemampuan membaca tulisan Arab sekitar $81,25 \%$ pada kategori baik, dan persentase tertinggi kemampuan melafalkan tulisan Arab sekitar $81,25 \%$ pada kategori baik. Dengan demikian, dapat kita simpulkan bahwa mahasiswa memiliki kemampuan yang baik pada aspek tulisan bahasa Arab, sehingga hal ini tidak menjadi problem utama bagi mahasiswa.

2. Aspek non-Linguistik

Pada aspek ini, peneliti mengggali data tempat tinggal mahasiswa dan hasilnya $43,75 \%$ mengatakan bahwa tempat tinggal cukup mempengaruhi proses pembelajaran maharah qira'ah. Hal ini bisa disebabkan karena banyak mahasiswa yang tinggal di daerah yang jauh dari kampus ataupun daerah perkotaan, sehingga akses internet ataupun akses ke kampus tidak bisa maksimal dilakukan.

Pada aspek penyajian materi, $68,75 \%$ mahasiswa menyebutkan bahwa penyajian materi yang diberikan mempengaruhi proses pembelajaran maharah qira'ah. 
Pada aspek tulisan yang digunakan pada materi qira'ah, 81,25\% mahasiswa menyebutkan bahwa tulisan yang digunakan mempengaruhi proses pembelajaran maharah qira'ah.

Pada aspek penggunaan media pembelajaran daring, 100\% mahasiswa mengatakan bahwa yang menjadi kendala mereka dalam pembelajaran daring adalah seringnya sinyal hilang yang disebabkan oleh cuaca atau listrik padam.

\section{Hasil dan Pembahasan}

Berdasarkan hasil yang dipaparkan di atas, maka dapat dilihat bahwa problem utama yang menjadi penghambat mahasiswa dalam mengikuti perkuliahan maharah qira'ah adalah pada aspek penguasaan tata bahasa yang dimiliki oleh mahasiswa. Pada perkuliahan maharah qiraah mahasiswa diharuskan mampu membaca kitab turats yang di dalamnya terdapat tulisan Bahasa Arab tanpa harakat. Oleh karena itu, mahasiswa dituntut untuk menguasai ilmu nahwu maupun ilmu sharf.

Hal tersebut tentunya berbeda dengan kemampuan membaca pada siswa di Madrasah dimana teks yang mereka baca masih memiliki harakat. Jadi, mereka hanya dituntut untuk bisa membaca tulisan yang sudah memiliki harakat tersebut dan memahami isi dari teks tersebut.

Problematika pada aspek non-linguistik, seperti yang telah dipaparkan pada penelitian sebelumnya, menyebutkan bahwa kepemilikan smartphone, kurangnya sinyal dan terbatasnya kuota internet tidak menjadi masalah utama bagi mahasiswa. Hal ini disebabkan karena 100\% mahasiswa memiliki smartphone sendiri dan sudah memiliki kesadaran untuk menyediakan kuota internet khusus untuk belajar, serta mencari tempat yang benar-benar mendukung untuk melaksanakan perkuliahan secara daring, seperti tinggal di kos yang dekat dengan daerah perkotaan atau sekitar kampus. Namun demikian, sewaktu-waktu masalah sinyal bisa menjadi kendala jika cuaca tidak mendukung atau listrik padam, yang menyebabkan sistem jaringan internetpun ikut terhambat.

Berdasarkan hal tersebut dapat dilihat bahwa yang menjadi problem utama bagi mahasiswa PBA IAIN SAS Bangka Belitung dalam pembelajaran qira'ah adalah pada kemampuan memahami kaidah Bahasa arab serta implementasinya dalam membaca teks arab. 
Adapun pada aspek kosa kata, mahasiswa sudah cukup mahir memanfaatkan teknologi yang sudah ada, sehingga masalah tersebut bisa teratasi. Sedangkan dalam aspek penuntasan tugas dari dosen, mahasiswa di lingkungan PBA IAIN SAS Bangka Belitung sudah memiliki kesadaran masing-masing untuk menuntaskan penugasan yang diberikan oleh dosen pengampu.

\section{Kesimpulan}

Berdasarkan hasil dan pembahasan di atas dapat disimpulkan bahwa problematika pembelajarann maharah qiraah yang dihadapi oleh mahasiswa Prodi PBA IAIN SAS Bangka Belitung meliputi: 1) Aspek linguistik. Lebih dari 50\% mahasiswa memiliki kemampuan memahami kaidah Bahasa Arab yang kurang baik, terutama pada penguasaan ilmu nahwu dan ilmu sharf; dan 2) Pada aspek nonlinguistik tidak terdapat problem yang berarti, kecuali adanya masalah pada jaringan yang sesekali hilang yang disebabkan oleh perubahan cuaca ataupun listrik padam.

Berdasarkan tujuan awal penelitian ini, yaitu ingin mengetahui masalah-masalah yang muncul sebagai akibat dari pelaksanaan pembelajaran secara daring dalam perkuliahan maharah qira'ah, maka peneliti mengharap agar penelitian ini dapat menjadi rujukan bagi para pengajar Bahasa Arab dalam memilih media yang tepat serta metode yang paling efektif dan efisien untuk memaksimalkan jalannya pembelajaran maharah qiraah secara daring. Selanjutnya, bagi para peneliti di bidang pembelajaran Bahasa Arab maupun peneliti di bidang pendidikan pada umumnya, penelitian ini dapat menjadi referensi untuk mengoptimalkan penelitian-penelitian yang berkaitan dengan pembelajaran daring. 


\section{Daftar Pustaka}

Ana, Saiul. "PEMBELAJARAN BAHASA ARAB DARING (Studi Kasus Mahasiswa Hukum Kelurga Islam (HKI) STAI Taruna Surabaya)", Al-Fakkaar, Vol. 1, No. 2, 2020.

Asyrofi, Syamsuddin, Metodologi Pembelajaran Bahasa Arab, Yogyakarta: Idea Press, 2010.

Corinna, Dwi Felita, Intan Rembulan, and Faisal Hendra. "PROBLEMATIKA PEMBELAJARAN BAHASA ARAB SECARA DARING: STUDI KASUS MAHASISWA PROGRAM STUDI BAHASA DAN KEBUDAYAAN ARAB UNIVERSITAS AL-AZHAR INDONESIA", Prosiding Konferensi Nasional Bahasa Arab, Vol. 6, No. 6, 2020.

Fadilla, Annisa Nurul, Ayu Suci Relawati, and Nani Ratnaningsih. "PROBLEMATIKA PEMBELAJARAN DARING PADA PEMBELAJARAN MATEMATIKA DI MASA PANDEMI COVID-19", Jurnal Jendela Pendidikan, Vol. 1, No. 02, 2021.

Haryadi, Rudi and Fitria Selviani. "PROBLEMATIKA PEMBELAJARAN DARING DI MASA PANDEMI COVID-19", Academy of Education Journal, Vol. 12, No. 2, 2021.

Hermawan, Acep, Metodologi Pembelajaran Bahasa Arab, Bandung: PT. Remaja Rosdakarya, 2011.

Morrisan, Metode Penelitian Survei, 5th edition, Depok: Prenada Media Group, 2018.

Nengrum, Thityn Ayu, Najamuddin Pettasolong, and Muhammad Nuriman. "Kelebihan dan Kekurangan Pembelajaran Luring dan Daring dalam Pencapaian Kompetensi Dasar Kurikulum Bahasa Arab di Madrasah Ibtidaiyah 2 Kabupaten Gorontalo", Jurnal Pendidikan, Vol. 30, No. 1, 2021.

Rathomi, Ahmad. "Pembelajaran Bahasa Arab Maharah Qira'Ah Melalui Pendekatan Saintifik", Ta'dib: Jurnal Pendidikan Islam, Vol. 8, No. 1, 2019.

SHINTIA, WULANDARI, Mahluddin Mahluddin, and Imran Imran. "PROBLEMATIKA GURU SELAMA PEMBELAJARAN DARING DENGAN MENGGUNAKAN APLIKASI WHATSAPP GROUP 
ALIBBAA': Jurnal Pendidikan Bahasa Arab, 2 (2), 2021

PADA MATA PELAJARAN BAHASA ARAB PADA SISWA KELAS $V$ DI MI AN-NIZHAM KOTA JAMBI", UIN Sulthan Thaha Saifuddin Jambi, 2021.

Syagif, Ahmad. "PROBLEMATIKA PEMBELAJARAN BAHASA ARAB MENGGUNAKAN APLIKASI WHATSAPP SELAMA PANDEMI COVID-19 PADA SISWA MADRASAH IBTIDA'IYAH DI KOTA BIMA", Fashluna: Jurnal Pendidikan Dasar Dan Keguruan, Vol. 1, No. 02, 2020. 